\title{
Association between serum uric acid and inflammation markers in ankylosing spondylitis patients treated with tumor necrosis factor- $\alpha$ or nonsteroidal anti-inflammatory drugs
}

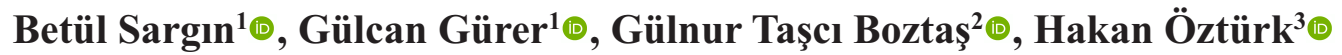 \\ ${ }^{1}$ Department of Physical Medicine and Rehabilitation, Division of Rheumatology, Adnan Menderes University School of Medicine, \\ Aydin, Turkey \\ ${ }^{2}$ Department of Physical Medicine and Rehabilitation, Adnan Menderes University School of Medicine, Aydin, Turkey \\ ${ }^{3}$ Department of Biostatistics, Adnan Menderes University School of Medicine, Aydin, Turkey
}

DOI: $10.18621 /$ eurj.359504

\begin{abstract}
Objectives: Uric acid has an important role in the production of various inflammatory cytokines such as tumor necrosis factor- $\alpha$ (TNF- $\alpha)$. Although serum uric acid levels in various rheumatic diseases have been performed the relationships between serum uric acid levels with inflammatory markers and Bath Ankylosing Spondylitis Disease Activity Index (BASDAI) scores in ankylosing spondylitis patients treated with anti-TNF- $\alpha$ and nonsteroid anti-inflammatory drugs (NSAIDs) have not been described yet. The aim of this study was to compare the relationships between serum uric acid levels, inflammatory markers and BASDAI scores in ankylosing spondylitis patients treated anti-TNF- $\alpha$ and NSAIDs.

Methods: A total of 132 ankylosing spondylitis patients fulfilling the 1984 Modified New York Criteria who had serum uric acid, erythrocyte sedimentation rate and C-reactive protein levels in medical records were included in this retrospective cross-sectional study. Patients were divided in two groups (anti-TNF- $\alpha$ and NSAIDs). Their files were examined in detail. Later demographic and laboratory features were recorded to the research form.

Results: Serum uric acid levels were significantly lower in the anti-TNF- $\alpha$ group (mean: $4.9 \mathrm{mg} / \mathrm{dL}$, range: $4.10-5.45 \mathrm{mg} / \mathrm{dL}$ ) than in the NSAIDs group (mean: $5.20 \mathrm{mg} / \mathrm{dL}$, range 4.70-5.90 mg/dL) $(p=0.021)$. Also, positive correlations were found between C-reactive protein $(p=0.003)$ and BASDAI $(p=0.009)$ with serum uric acid.

Conclusions: According to this study, we can consider that serum uric acid level could be used as an inflammatory laboratory marker, such as C-reactive protein in ankylosing spondylitis patients. However, we believe that more studies are needed about this research.
\end{abstract}

Keywords: Uric acid, inflammation, ankylosing spondylitis

Received: November 29, 2017; Accepted: January 21, 2018; Published Online: April 1, 2018

A nkylosing spondylitis (AS) is an inflammatory rheumatic disorder and a prototype of spondyloarthritis, characterized by axial skeleton and sacroiliac joint involvement. About $90 \%$ of patients develop the first symptoms before $40-45$ years and the average age is 28.3 [1].

Uric acid is an end product of purine metabolism [2]. It has been found to induce monocyte

Address for correspondence: Betül Sargin, MD., Assistant Professor, Adnan Menderes University School of Medicine, Department of Physical Medicine and Rehabilitation, Division of Rheumatology, Aydin, Turkey

E-mailbetul.cakir@yahoo.com, betulcakir834@gmail.com,Fax:+90-256-2136064 
chemoattractant protein-1 (MCP-1) from vascular smooth muscle cells through activation of nuclear factor- $\kappa \mathrm{B}(\mathrm{NF}-\kappa \mathrm{B})$ and $\mathrm{p} 38$ mitogen-activated protein kinase (MAPK) [3]. Uric acid stimulates production of proinflammatory cytokines such as tumor necrosis factor- $\alpha$ (TNF- $\alpha)$, IL-1 $\beta$, IL- 6 and IL-8 from mononuclear cells [4]. NF- $\kappa \mathrm{B}$ signalling pathway leads to the production of various inflammatory cytokines such as IL- $1 \beta$, TNF- $\alpha$ [5].

Some studies about serum uric acid (SUA) levels in various rheumatic diseases such as rheumatoid arthritis (RA) [6], systemic lupus erythematosus (SLE) [7], psoriasis [8-11], and AS [15] has been performed. We also compared to the SUA levels in AS patients treated with anti-TNF- $\alpha$ and nonsteroid antiinflammatory drugs (NSAIDs) in present study. Futhermore, we investigated the relationships between SUA levels with erythrocyte sedimentation rates (ESR) and C-reactive protein (CRP) values and Bath Ankylosing Spondylitis Disease Activity Index (BASDAI) scores. To the authors' knowledge, this is the first study in AS patients which evaluated the relationships between SUA levels with inflammatory markers and BASDAI scores. We aimed to determine that SUA level could be used as an inflammatory laboratory marker, such as CRP in AS patients.

\section{METHODS}

Our study was carried out at Department of Physical Medicine and Rehabilitation, Division of Rheumatology, Aydın, Turkey from January 2017 to June 2017. The ethics committee of the Institution approved the study and all patients signed the Informed consent form. One hunded ninety-one patients who were diagnosed with AS according to the 1984 Modified New York criteria were included. We determined that 18 patients had no SUA levels in medical records. Kidney failure was existed in one patient, nonalcoholic fatty liver disease was existed in five patient, peripheral arterial disease was existed in five patient, hypertension was existed in five patient, cardiovascular diseases was existed in five patient, diabetes mellitus was existed in five patient. Four patient hypoglycemic agent, four patient lipidlowering drug, four patient angiotensin-converting enzyme inhibitor, three patient corticosteroids were using. Therefore, a total of 59 patients were excluded from the study.

Fourty-nine (32 male, 17 female) patients were treated with anti-TNF $\alpha$ and 83 (47 male, 36 female) patients were treated with NSAIDs. We examined patients' files in detail and recorded ages, genders, use of drugs, BASDAI scores, erythrocyte sedimentation rate (ESR), C-reactive protein (CRP) and SUA levels to the research form. SUA levels of the patients before anti-TNF $\alpha$ and NSAIDs uses were checked from medical records.

Demographic features of patients were presented in Table 1. We used BASDAI which is a tool for evaluation of disease activity in AS patients. SUA level is measured by spectrophotometric assay (Abbott Diagnostics) in our hospital.

The patients' SUA status are defined as the following: (1) Normal: SUA level normal ranges (2.6$6 \mathrm{mg} / \mathrm{dL}$ ); (2) Hypouricemia: SUA level lower than $2.6 \mathrm{mg} / \mathrm{dL}$; and (3) Hyperuricemia: SUA level over 6 $\mathrm{mg} / \mathrm{dL}[16]$.

ESR (normal range: $0-20 \mathrm{~mm} / \mathrm{h}$ ) is analysed by Westergren method using Vacuplus (Roche). CRP (normal range: $0-5 \mathrm{mg} / \mathrm{L}$ ) is analysed by turbidimetry test using Prestij (Abbott Diagnostics) in our hospital.

Exclusion criteria for our study were pregnancy, lactation, presence of additional co-morbidities (metabolic syndrome, diabetes mellitus, dyslipidemia, nonalcoholic fatty liver disease, cardiovascular diseases, peripheral arterial disease, hypertension, kidney failure, etc). In addition to these disorders, patients who had use of several kinds of drugs such as hypoglycemic agents (metformin), weight-reducing drugs (orlistat), lipid-lowering drugs (fenofibrate, simvastatin, ezetimibe, atorvastatin), calcium channel blockers (amlodipine), angiotensin-converting enzyme inhibitors (captopril, enalapril, ramipril), angiotensin II receptor antagonists (losartan), estrogens, corticosteroids, and the dietary food supplements vitamin $C$, vitamin $A$, iron, flavonoids, omega 3 fatty acids, zinc and $\beta$-carotene were excluded. Since these conditions can altere SUA levels we determined them as exclusion criterias.

\section{Statistical Analysis}

T-test was applied to compare for normally distributed variables. Mann-Whitney $U$ test was applied to compare for non-normally distributed 
Table 1. Demographic and laboratory features of patients with ankylosing spondylitis

\begin{tabular}{|c|c|c|c|}
\hline & $\begin{array}{c}\text { Anti-TNF- } \alpha \text { group } \\
(n=49)\end{array}$ & $\begin{array}{c}\text { NSAIDs group } \\
(\mathbf{n}=\mathbf{8 3})\end{array}$ & $p$ value \\
\hline Age (years) & $41.4 \pm 9.5$ & $44.4 \pm 11.1$ & 0.148 \\
\hline Gender & & & 0.424 \\
\hline Male & $32(24.2 \%)$ & $47(35.6 \%)$ & \\
\hline Female & $17(12.9 \%)$ & $36(27.3 \%)$ & \\
\hline Disease duration (years) & $15.5(7.5-18.6)$ & $16.2(7.7-19.8)$ & 0.640 \\
\hline BMI $\left(\mathrm{kg} / \mathrm{m}^{2}\right)$ & $26.6 \pm 4.4$ & $27.8 \pm 4.6$ & 0.117 \\
\hline $\operatorname{AST}(\mathbf{U} / \mathbf{L})$ & $18.0(14.5-21.5)$ & $20.0(16.0-24.0)$ & 0.085 \\
\hline $\operatorname{ALT}(\mathbf{U} / \mathbf{L})$ & $19.0(15.0-23.5)$ & $20.0(15.0-30.0)$ & 0.110 \\
\hline Urea (mg/dL) & $27.0(21.0-34.0)$ & $26.0(22.0-34.0)$ & 0.861 \\
\hline Creatinine (mg/dL) & $0.77(0.70-0.84)$ & $0.75(0.70-0.82)$ & 0.463 \\
\hline Uric acid (mg/dL) & $4.90(4.10-5.40)$ & $5.40(4.40-6.20)$ & 0.021 \\
\hline
\end{tabular}

variables. Correlations between ESR and CRP levels with SUA levels and SUA and BASDAI of the all patients were assessed using Spearman's correlation test. Statistical analyses were carried out using the Statistical Package for the Social Sciences (SPSS), ver 19.0 ( IBM Corp.; Armonk, NY, USA) and $p<0.05$ was considered to be statistically significant.

\section{RESULTS}

Significant difference was not found among groups in terms of age, sex and BMI $(p>0.05)$. The mean age of AS patients in the anti-TNF- $\alpha$ group was $41.4 \pm 9.5$ years and $44.4 \pm 11.1$ years in the NSAIDs group (Table 1). The gender distribution was 17 women and 32 men among the patients with anti-TNF$\alpha$ group and 36 women and 47 men among the NSAID group. Mean disease duration was $16.3 \pm 9.8$ years for

Table 2. Correlations between serum uric acid levels with ESR, CRP levels and BASDAI of the ankylosing spondylitis patients

\begin{tabular}{rccc}
\hline & $\begin{array}{c}\text { ESR } \\
(\mathbf{m m} / \mathbf{h})\end{array}$ & $\begin{array}{c}\text { CRP } \\
(\mathbf{m g} / \mathbf{L})\end{array}$ & BASDAI \\
\hline $\begin{array}{c}\text { Uric acid } \\
(\mathbf{m g} / \mathbf{d L})\end{array}$ & & & \\
$\mathbf{r}$ & -0.063 & 0.228 & 0.148 \\
$\boldsymbol{p}$ & 0.415 & $\mathbf{0 . 0 0 3}$ & $\mathbf{0 . 0 0 9}$ \\
\hline
\end{tabular}

BASDAI $=$ Bath Ankylosing Spondylitis Disease Activity Index, $\mathrm{CRP}=\mathrm{C}$-reactive protein, $\mathrm{ESR}=$ erythrocyte sedimentation rates
anti-TNF- $\alpha$ group and $16.6 \pm 12.3$ years for NSAID group. Mean BMI $(\mathrm{kg} / \mathrm{m} 2)$ was $26.6 \pm 4.4$ for antiTNF- $\alpha$ group and $27.8 \pm 4.6$ for NSAID group. The mean AST level was $18.0 \mathrm{U} / \mathrm{L}$ for anti-TNF- $\alpha$ group and 20.0 U/L for NSAID group ( $p>0.05)$. Mean ALT level was $19.0 \mathrm{U} / \mathrm{L}$ for anti-TNF- $\alpha$ group and $20.0 \mathrm{U} / \mathrm{L}$ for NSAID group $(p>0.05)$. Mean urea level was 27.0 $\mathrm{mg} / \mathrm{dL}$ for anti-TNF- $\alpha$ group and $26.0 \mathrm{mg} / \mathrm{dL}$ for NSAID group $(p>0.05)$. Mean creatinine level was $0.77 \mathrm{mg} / \mathrm{dL}$ for anti-TNF- $\alpha$ group and $0.75 \mathrm{mg} / \mathrm{dL}$ for NSAID group $(p>0.05)$ (Table 1).

Serum uric acid levels were significantly lower in the anti-TNF- $\alpha$ group (mean: $4.9 \mathrm{mg} / \mathrm{dL}$, range: $4.10-5.45$ $\mathrm{mg} / \mathrm{dL}$ ) than in the NSAIDs group (mean: $5.20 \mathrm{mg} / \mathrm{dL}$, range 4.70-5.90 mg/dL) $(p=0.021))$ (see Table 1).

Positive correlations were found between SUA levels with CRP levels $(\mathrm{r}=0.228, p=0.003)$ and BASDAI $(r=0.148, p=0.009)$ (Table 2).

\section{DISCUSSION}

Serum uric acid levels were investigated in various rheumatic diseases $[6-11,15]$. Choe et al. [6] studied SUA levels in RA patients and it's association between inflammatory markers such as ESR and CRP in 23 patients treated with methotrexate (MTX) and 27 patients treated with MTX and leflunomide. They reported that leflunomide was reduced SUA levels. However they anounced that any correlation between 
SUA levels with inflammatory markers was not found. Sheikh et al. [7] detected hyperuricemia in $16.1 \%$ of 204 SLE patients and found that hyperuricemia was associated with the occurrence of stroke, peripheral neuropathy, hypertension, hyperlipidemia, and history of arterial thrombosis. Also, SUA levels were studied in psoriasis patients [8-11]. Prasad et al. [8] studied SUA and rheumatoid factor levels in 472 psoriasis patients and in outcome, found that SUA levels were above normal in 18 out of the $40(45 \%)$ psoriatic patients. Kwon et al. [9] investigated SUA levels and it's correlation between Psoriasis Area and Severity Index (PASI) in 198 Korean patients with psoriasis. As a result of this study, SUA levels was not significantly different from healthy population $(p>$ $0.05)$. They found a positive correlation between SUA levels and PASI. They proposed that an increased epidermal cell turnover could be an important cause of raised SUA in psoriasis patients. Gisondi et al. [10] researched SUA levels in 119 psoriatic patients and 119 healty controls. They found higher SUA levels in psoriatic patients (psoriatic patients, mean: SUA: 5.61 $\pm 1.6 \mathrm{mg} / \mathrm{dL}$, healty controls, mean: SUA: $4.87 \pm 1.4$ $\mathrm{mg} / \mathrm{dL}$ ). They suggested that hyperuricaemia in psoriasis could be simply a consequence of obesity, metabolic disorders, and psoriasis itself. Li et al. [11] explained a meta-analysis to identify the SUA levels in subjects with psoriasis and to determine whether there is an associated risk between psoriasis and hyperuricemia.

Kanellis et al. [12] announced that UA is a mediator of endothelial dysfunction, inflammation and vascular disease including hypertension and atherosclerosis. It's inflammatory and proliferative effects have been described on vascular smooth muscle cells (VSMCs). It's effects on the vasculature have been linked to increased chemokine and cytokine expression, induction of the renin-angiotensin system, and to increased vascular CRP expression. Correlation between SUA and CRP has been investigated in two studies. In Isha et al's study [13] 25 new psoriatic patients having active disease, 25 patients of various skin diseases other than psoriatic lesion and 25 normal subjects were included before and after 12 weeks of treatment. In conclusion, mean SUA concentation was found to be significantly higher in patients with psoriasis $(p<0.05)$. After 12 weeks of treatment, mean value for SUA was found to be significantly decreased $(p<0.05)$. Mean value for CRP was found to be increased by more than 20 folds in patients with psoriasis, which was subsequently reduced to nearly $50 \%$ of the initial value after 12 weeks of treatment. These patients also showed hyperuricemia. They suggested that both CRP and UA levels should be monitored in patients with psoriasis. In the other study, Lyngdoh et al. [14] evaluated the association between SUA levels with CRP, TNF- $\alpha$, interleukin-6 (IL-6) and interleukin-1 $\beta$ (IL-1 $\beta$ ) levels in 6085 healty participants. As a result of their study SUA was associated positively with CRP $(p<0.001), \mathrm{TNF}-\alpha(p$ $<0.001)$ and IL-6 $(p<0.001)$, and negatively with IL$1 \beta(p=0.027)$. These results suggested that UA contributes to systemic inflammation and may have a role in inflammation and subsequent inflammatory related diseases.

In the scanning literature, there is only one study according to our scan results that investigated SUA levels in the AS patients [15]. In this study, it was reported that hyperuricemia was found in 5 of $23 \mathrm{AS}$ patients. These patients had a higher frequency of uveitis, lesser degree of clinical activity of the disease $(p<0.001)$, lower levels of ESR $(p<0.05)$, a lesser degree of ankylosis of the spine and a better functional prognosis. Normouricemia was found in 8 of 23 AS patients. As a result of their study they report that seri analysis of UA can determine the prognosis.

As a result of our study we found positive correlations between SUA levels with CRP levels and BASDAI scores. However, we did not detected any a correlation among SUA and ESR levels. CRP as a better acute phase reactant than ESR in AS patients was indicated in some studies [17-19]. SUA levels were significantly lower in the anti-TNF- $\alpha$ group than in the NSAIDs group. As a result, anti-TNF- $\alpha$ treatment suppresses inflammatory process more strongly, so we may have found lower levels of SUA in anti-TNF- $\alpha$ group. But more randomised controlled studies are needed to demonstrate these findings.

\section{CONCLUSION}

According to this study, we can consider that SUA level could be used as an inflammatory laboratory 
marker, such as CRP in AS patients. However, we believe that more studies are needed about this research.

\section{Conflict of interest}

The authors disclosed no conflict of interest during the preparation or publication of this manuscript.

\section{Financing}

The authors disclosed that they did not receive any grant during conduction or writing of this study.

\section{REFERENCES}

[1] Reveille JD, Weisman MH. The epidemiology of back pain, axial spondyloarthritis and HLA-B27 in the United States. Am J Med Sci 2013;345:431-6.

[2] Choi HK, Mount DB, Reginato AM. Pathogenesis of gout. Ann Intern Med 2005;143: 499-516.

[3] Kanellis J, Watanabe S, Li JH, Kang DH, Li P, Nakagawa T, et al. Uric acid stimulate monocyte chemoattractant protein-1 production in vascular smooth muscle cells via mitogen-activated protein kinase and cyclooxygenase-2. Hypertension 2003;41:1287-93.

[4] Johnson RJ, Kang DH, Feig D, Kivlighn S, Kanellis J, Watanabe S, et al. Is there a pathogenetic role for uric acid in hypertension and cardiovascular and renal disease? Hypertension 2003;41:1183-90.

[5] Oeckinghaus A, Ghosh S. The NF-kappaB family of transcription factors and its regulation. Cold Spring Harb Perspect Biol 2009;1:a000034.

[6] Choe JY, Kim SK. Association between serum uric acid and inflammation in rheumatoid arthritis: perspective on lowering serum uric acid of leflunomide. Clin Chim Acta 2015;438:29-34.

[7] Sheikh M, Movassaghi S, Khaledi M, Moghaddassi M. Hyperuricemia in systemic lupus erythematosus: is it associated with the neuropsychiatric manifestations of the disease? Rev Bras Reumatol Engl Ed 2016;56:471-77.

[8] Prasad PV, Bikku B, Kaviarasan PK, Senthilnathan A. A clinical study of psoriatic arthropathy. Indian J Dermatol Venereol Leprol 2007;73:166-70.

[9] Kwon HH, Kwon IH, Choi JW, Youn JI. Cross-sectional study on the correlation of serum uric acid with disease severity in Korean patients with psoriasis. Clin Exp Dermatol 2011;36:473-8.

[10] Gisondi P, Targher G, Cagalli A, Girolomoni G. Hyperuricemia in patients with chronic plaque psoriasis. J Am Acad Dermatol 2014;70:127-30.

[11] Li X, Miao X, Wang H, Wang Y, Li F, Yang Q, et al. Association of serum uric acid levels in psoriasis: a systematic review and metaanalysis. Medicine (Baltimore) 2016;95:e3676.

[12] Kanellis J, Kang DH. Uric acid as a mediator of endothelial dysfunction, inflammation, and vascular disease. Semin Nephrol 2005;25:39-42.

[13] Isha VK, Lal JH. C-reactive protein and uric Acid levels in patients with psoriasis. Ind J Clin Biochem 2011;26:309-11.

[14] Lyngdoh T, Marques-Vidal P, Paccaud F, Preisig M, Waeber G, Bochud M, et al. Elevated serum uric acid is associated with high circulating inflammatory cytokines in the population-based Colaus study. PLoS One 2011;6:e19901.

[15] Jiménez Balderas FJ, Robles EJ, Juan L, Badui E, Arellano H, Espinosa Said L, et al. Purine metabolism in ankylosing spondylitis: clinical study. Arch Invest Med (Mex) 1989;20:163-70.

[16] Van Leeuwen AM, Bladh ML. Davis's Comprehensive Handbook of Laboratory and Diagnostic Tests with Nursing Implications. 6th ed. Philadelphia, PA: PA. Davis Company, 2015., p.329.

[17] Nashel DJ, Petrone DL, Ulmer CC, Sliwinski AJ. C-reactive protein: a marker for disease activity in ankylosing spondylitis and Reiter's syndrome. J Rheumatol 1986;13:364-7.

[18] Benhamou M, Gossec L, Dougados M. Clinical relevance of Creactive protein in ankylosing spondylitis and evaluation of the NSAIDs/coxibs' treatment effect on C-reactive protein. Rheumatology (Oxford) 2010;49:536-41.

[19] Siebuhr AS, Bay-Jensen AC, Karsdal MA, Lories RJ, de Vlam K. CRP and a biomarker of type I collagen degradation, C1M, can differentiate anti inflammatory treatment response in ankylosing spondylitis. Biomark Med 2016;10:197-208. 